\title{
Is There a Need for Contrast and Local Anesthetic in Cervical Epidural Steroid Injections?
}

W e read with great interest the recent article by Lagemann et $\mathrm{al}^{1}$ regarding the extraforaminal needle tip position for CT-fluoroscopic cervical transforaminal epidural steroid injections to reduce the risk of intravascular injection.

The technique for injection is outlined in the "Materials and Methods" section. The authors administered a trial dose of $0.3 \mathrm{~mL}$ of iohexol contrast (Omnipaque 300; GE Healthcare, Piscataway, New Jersey) to determine whether the needle was intravascular, followed by a cocktail of $1.2 \mathrm{~mL}$ of $2.5-5 \mathrm{mg} / \mathrm{mL}$ of bupivacaine analgesic, $8 \mathrm{mg}$ of dexamethasone, and $0.3 \mathrm{~mL}$ of iohexol.

First, we question the use of bupivacaine in transforaminal epidural steroid injections. The inadvertent intravascular injection of bupivacaine has been associated with vasospasms of arterioles and increases the risk of CNS infarction. ${ }^{2}$ There is also no lasting analgesic benefit from the extraforaminal injection of local anesthetic; thus, we propose the use of local anesthetic to the skin at the time of induction of the needle and none further in the procedure.

As highlighted in our Letter previously published in this journal, we question the use of contrast in cervical injections. ${ }^{3}$ The inclusion of contrast gives the radiologist a false sense of security (as seen in the article by Lagemann et al with over half [55\%] of the intravascular injections of dexamethasone having no evidence of the intravascular positioning on the trial contrast dose). Realtime imaging, such as digital subtraction angiography, would be needed to accurately detect the intravascular injection. Evidence shows that dexamethasone is likely safe when inadvertently in-

http://dx.doi.org/10.3174/ajnr.A4881 jected intravascularly. ${ }^{4,5}$ By including contrast in this cocktail, you also introduce the risk of contrast reaction. Given the lack of adverse events with intravascular injection of dexamethasone and the poor sensitivity for identifying intravascular positioning, we propose the omission of contrast from this procedure.

In our center during the past 8 years of transforaminal extraforaminal injections with this technique, there have been no adverse events. We propose the use of a small volume of $1 \%$ lidocaine to the skin and $2-8 \mathrm{mg}$ of dexamethasone injected extraforaminally under CT guidance.

\section{REFERENCES}

1. Lagemann GM, Yannes MP, Ghodadra A, et al. CT-fluoroscopic cervical transforaminal epidural steroid injections: extraforaminal needle tip position decreases risk of intravascular injection. AJNR Am J Neuroradiol 2016;37:766-72 CrossRef Medline

2. MacMahon PJ, Eustace SJ, Kavanagh EC. Injectable corticosteroid and local anesthetic preparations: a review for radiologists. Radiology 2009;252:647-61 CrossRef Medline

3. Ryan TM, Kavanagh EC, MacMahon PJ. Is there a need for contrast administration prior to CT-guided cervical nerve root block? AJNR Am J Neuroradiol 2013;34:E45 CrossRef Medline

4. Scanlon GC, Moeller-Bertram T, Romanowsky SM, et al. Cervical transforaminal epidural steroid injections: more dangerous than we think? Spine 2007;32:1249-56 CrossRef Medline

5. Okubadejo GO, Talcott MR, Schmidt RE, et al. Perils of intravascular methylprednisolone injection into the vertebral artery: an animal study. J Bone Joint Surg Am 2008;90:1932-38 CrossRef Medline

(i) M.P. Bolger (1) P.J. MacMahon

(1)E.C. Kavanagh

Department of Radiology Mater Misericordiae University Hospital Dublin, Ireland 